\title{
Reduction of commercial aircraft noise emission around airports. A new environmental challenge
}

\author{
Salah Khardi
}

Received: 23 September 2008 / Accepted: 9 November 2009/Published online: 3 December 2009

(C) European Conference of Transport Research Institutes (ECTRI) 2009

\begin{abstract}
Noise abatement procedures (NAPs) are considered as a necessary measure for a balanced approach of noise control around airports. Their correct implementation depends upon many factors, which vary in operation and influence the efficiency of the NAPs. Any system, which defines the correct features of the NAPs for particular aircraft in specific conditions, would be useful for noise control. Thus, implementation of noise level monitoring systems, currently used around airports, gives a noise map in residential areas but cannot identify source frequencies and their impact on the environment. Consequently, this paper has been produced particularly to characterize the frequential aspect of aircraft noise emission. Its main objective is the analysis of the dominant frequencies emitted during approaches to the Lyon Saint-Exupéry International Airport (France) having a negative impact on the population living around this airport. Thus, the results obtained make it possible to show, through an empirical model of aircraft noise, the effectiveness of this experimental work.
\end{abstract}

Keywords Aircraft noise $\cdot$ Noise abatement procedures . Noise reduction $\cdot$ Pure frequencies $\cdot$ Noise control system

\section{Introduction}

Environmental compatibility of aircraft operations is a critical issue that impacts the growth of commercial aviation. A number of major European airports have

\section{S. Khardi $(\bowtie)$}

INRETS-LTE. 25,

avenue François Mitterrand,

69675 Bron cedex, France

e-mail: Salah.khardi@inrets.fr reached their environmental capacity before having made full use of their runway and terminal infrastructures. One of the significant environmental challenges of the Advisory Council for Aeronautics Research in Europe (2020 vision) is the reduction of perceived external noise by $50 \%$ ( $-10 \mathrm{~dB} /$ operation). Different solutions have been attempted to control aircraft noise at airports. Nevertheless, the noise in the vicinity of airports, in particular under the takeoff and landing flight paths remains high and disrupts the quality of life of local residents.

Technology solutions and the measures taken by airport authorities (restrictions on use of land, procedures for takeoff and landing, operating restrictions, compensating residents, ...), have failed to reduce aircraft noise impact because of the growth in air traffic. The aircraft manufacturers foresee a demand for aircraft to cope with the increased traffic and fleet renewal in the coming years. This growth will be faced with two major challenges: 1. mass transport will have to anticipate the scarcity of take-off slots; 2. transport will have to increase frequency and the flexibility of operations despite the anticipated shortage of oil. This environmental problem can only be solved within the framework of a balanced global vision for a sustainable air transport involving new technology engines and fuselages [17], breakthrough technologies, the design of new procedures and flight paths [35], airspace management, new regulation rules and certification [8]. Commercial jet aircraft sources are active and their relative importance depends on the flight segment and the airframe-engine combination. There are many aircraft components producing noise (flaps, under-carriage, engines, etc.) with different noise characteristics depending, in particular, on operational flight configurations during approach and take-off. Nowadays, the lack of a clear link between the certified noise levels defined by aircraft manufacturers and noise levels 
measured on the ground generated from aircraft components during operations is well known. The high noise levels and their spectral features have not yet been well established during flight operations. Indeed, at the end of each certification, changes have taken place, due to technological leaps of aviation industries $[18,24]$. Identifying the dominant frequencies emitted by aircraft on approach which are responsible for the discomfort and the annoyance of local residents living around airports and the diagnosis of their origin is a major task to be carried out. In spite of the development of new technologies and initiatives to reduce the high noise levels and successive improvement of aircraft certification on the basis of the ICAO convention, the search of the emitted frequencies characterized by their high noise levels is still needed. Frequencies emitted by fan, turbine, compressor, jet noise and aerodynamic noise due to flows around the body of the aircraft cannot be identified in static conditions. They are all dominant and depend on the mode of operation or the engaged landing procedure. Thus, the study of dominant frequencies emitted during operations, and performed in this paper, should allow manufacturers to focus aircraft development on their reduction "in flight". Another advantage of this research is to reduce the computational time of noise propagation models often conducted in a wide frequency band. In the absence of data from specific studies on emitted frequencies in operation and their impact on the sound quality around airports, this research must be conducted. For a number of reasons, $40 \%$ of the used flight paths do not correspond to the theoretical flight plan published before the take-off. Those changes are generally related to operational conditions and are confirmed by radar track information. This argument is in favour of this work.

This paper gives spectral characteristics of aircraft noise during approaches. Measurements protocol of aircraft noise, established by the International Civil Aviation Organization "ICAO", is strictly respected and applied [12-14]. Results of this paper contribute to a better understanding of aircraft frequency emissions in operations and their control. First, the paper describes the measurement set up under which aircraft noise signals were recorded and data processed. The second section presents spectral methodology of data processing. The time signals are analyzed and their spectral features are carried out assuming aircraft noises on approach as unsteady states. Doppler Effect has been described and removed from the recorded noise signals with a suitable procedure which steps are detailed and interference patterns shown. The third section gives results and discusses, in particular, the origin of the pure dominating frequencies emitted by aircraft sources in-flight. Comparisons have been provided between the obtained results and those found in the open literature. Finally, we have shown the potential of this experimental work and its future prospects in the validation of the aircraft noise modeling.

\section{Experimental set up and analysis}

This section describes the measurement set up and conditions under which aircraft noise was recorded and data processed. We used approved procedures recommended by the ICAO [12] applied during acoustic tests and analysis of aircraft noise measurements. The measurements of noise generated by aircraft at approach were carried out in Saint-Exupéry Lyon International Airport for one year according to annex 16 of the ICAO convention. The noise signals were recorded so that we can assess noise exposure following indices based on A weighting (Equivalent sound level «L $\mathrm{L}_{\mathrm{Aeq}}$ », Sound Exposure Level «SEL», 10 percentileexceeded sound level $\left\langle\mathrm{L}_{10} »\right.$ (the A-weighted sound level occurred at $10 \%$ or more of the time of the measurement; $95 \%$ in case of $\left.\mathrm{L}_{95}\right)$, « $\mathrm{L}_{95} »$, Day-night averaged sound level « $\mathrm{L}_{\mathrm{DN}} »$, Level Day Evening Night $\left.« \mathrm{~L}_{\mathrm{den}} », \ldots\right)$. Locations for recording aircraft noise in flight are surrounded by flat terrain having no excessive sound absorption characteristics (grass fields cut). No obstructions that could influence the sound field from the aircraft within a conical space above the point on the ground vertically below the microphone exist. The cone being defined by an axis is normal to the ground and is half-angle $\left(80^{\circ}\right)$ from this axis. The type of aircraft was not recorded; it cannot be collected in real-time for each flight since it would require direct access to the flight data recorder.

Data were recorded in the four observation points designated in Fig. 1: under flight path at $2 \mathrm{~km} \pm 400 \mathrm{~m}$ lateral, and lateral to a $1,600 \mathrm{~m}$ runway and $500 \mathrm{~m}$ from the touch axis. Acoustic data stored under the flight path allows analysis of the frequencies issued without lateral and angular corrections and without the need for multiple systems of very expensive measurement stations. The two side points to $\pm 350 \mathrm{~m}$ are used to make an adjustment on the data especially when the trajectories practiced during the approach deviate from the main axis of the runway because of changes in runway landing (traffic regulation or an incident). The last measurement point is used to check the data when weather conditions change slightly and then air control modifies the direction of the aircraft approach operations. Measurements were performed under stable atmospheric conditions (Table 1).

The stability of atmospheric conditions was checked and timetabled. Table 1 shows their fluctuations in the intervals where stability criteria are met during measurements.

A SIP 95 sound level meter, a Symphony (01dB StellC), and a DAT FOSTEX PD-4 (44.1 kHz sampling frequency) were used to record the acoustic data. The measurement systems are inspected every two years and approved by the French National Laboratory for testing in accordance with international standards. The four microphones are positioned to $4 \mathrm{~m}$ above the ground to comply with the 
Fig. 1 Reception points under flight path and at lateral locations. Altitude of the $36 \mathrm{~L}$ and 18R points: $248 \mathrm{~m}$ and $231 \mathrm{~m}$. Altitude of the $36 \mathrm{R}$ and $18 \mathrm{~L}$ points: $250 \mathrm{~m}$ and $238 \mathrm{~m}$. Latitude and longitude of the 36 L point: $\left(45^{\circ} 42^{\prime} 39.31^{\prime \prime} \mathrm{N}\right)$ and $\left(5^{\circ} 05^{\prime} 24.34^{\prime \prime} \mathrm{E}\right)$

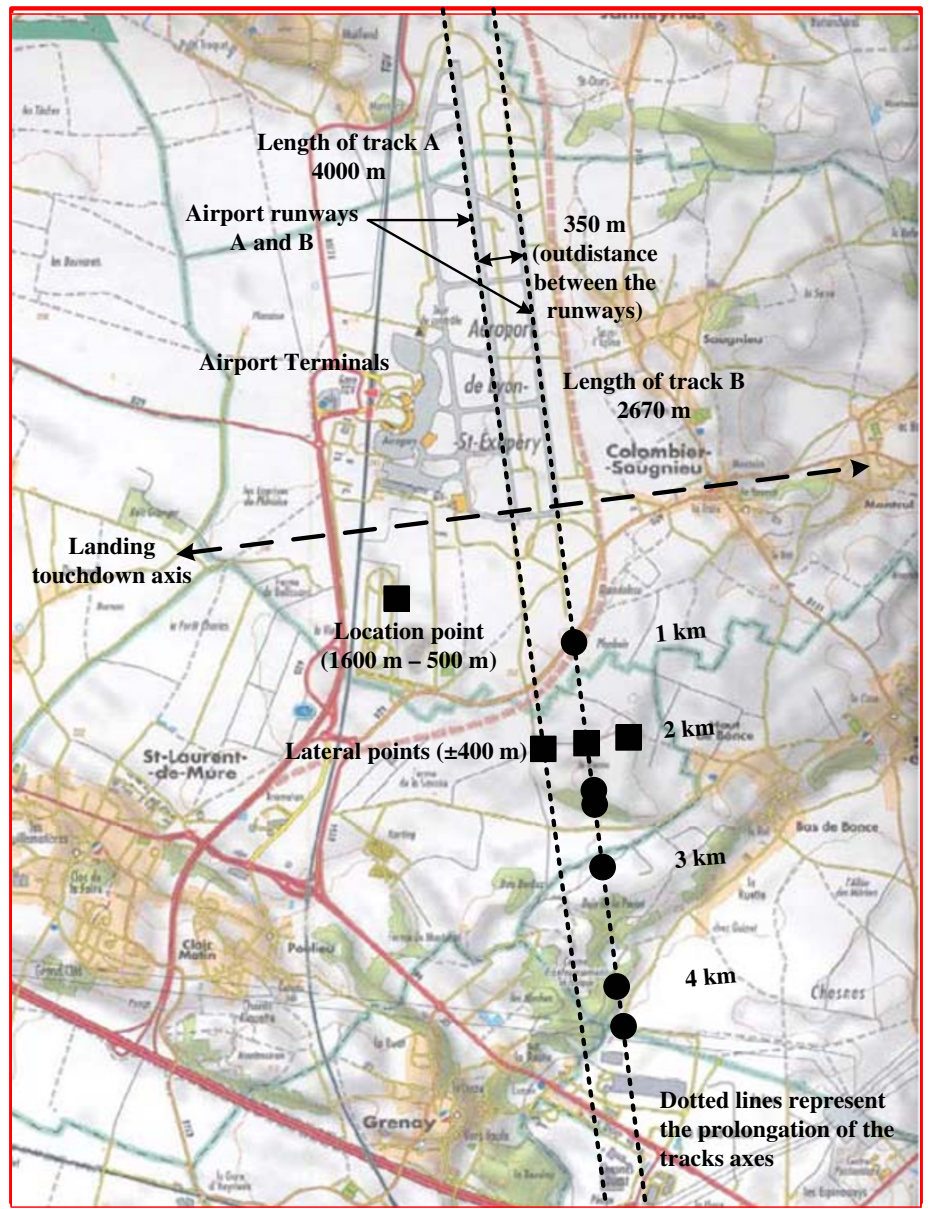

Runway A

North

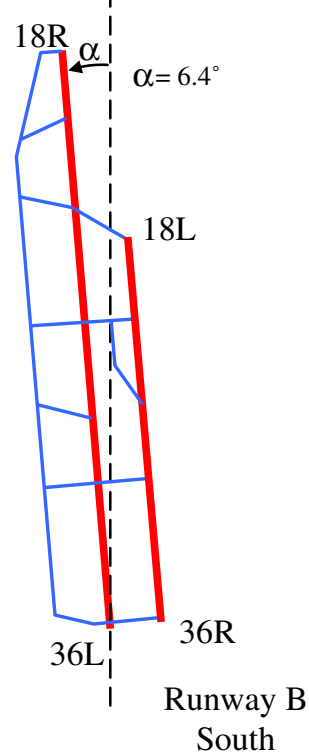

requirement of free fields. The ground is flat and consists of grass shorter without brush, wood or obstacles. Two calibrations are performed every day. The free-field sensitivity level of the microphone and preamplifier in the reference direction, at frequencies over at least the range of one-third-octave nominal midband frequencies from $50 \mathrm{~Hz}$ to $10 \mathrm{kHz}$ inclusive, is within $\pm 1.0 \mathrm{~dB}$ of that at the calibration check frequency, and within $\pm 2.0 \mathrm{~dB}$ for nominal midband frequencies of $6.3 \mathrm{kHz}, 8 \mathrm{kHz}$ and $10 \mathrm{kHz}$. The output of the analysis system consists of onethird octave band sound pressure levels as a function of time, obtained by processing the noise signals with the

Table 1 Meteorological parameters provided by Meteo France

\begin{tabular}{ll}
\hline Meteorological parameters (per hour) & Value intervals \\
\hline Wind speed $(\mathrm{m} / \mathrm{s})$ & $1-3$ \\
Average temperature $\left({ }^{\circ} \mathrm{C}\right)$ & $15-35$ \\
Cloudiness (octas) & $0-2$ \\
Humidity $(\%)$ & $35-50$ \\
Global radiation $(\mathrm{J} / \mathrm{cm} 3)$ & $240-290$ \\
\hline
\end{tabular}

following characteristics: a set of 24 one-third octave bands filters [50 Hz-10 kHz]; response and averaging properties in which the output from any one-third octave filter band is squared, averaged and displayed or stored as time-averaged sound pressure levels; the interval between successive sound pressure level samples is $500 \pm 5 \mathrm{~ms}$ for spectral analysis with or without slow time-weighting; and the sampling frequency is $44.1 \mathrm{kHz}$. Analysis system operated in real time from $50 \mathrm{~Hz}$ through at least $10 \mathrm{kHz}$ inclusive. Ambient noise, including both an acoustical background and electrical noise of the measurement system was recorded for $10 \mathrm{~min}$ a day with the system gain set at the levels used for the aircraft noise measurements. The recorded aircraft noise data is acceptable according to international standards, e.g. the ambient noise levels, when analyzed in the same way, are $20 \mathrm{~dB}$ below the maximum noise level of the aircraft. The reference interval used for defining noise exposure to the residents of the airport, taking into account human activities, corresponds to the periods of $6-18 \mathrm{~h}, 18-22 \mathrm{~h}$ and $22-6 \mathrm{~h}$. The exclusion criteria of the recorded data are: strike days and special weather conditions (gusty winds, stormy rainfall, atmospheric turbulence...). After each calibration, any level 
deviation greater than $1 \mathrm{~dB}$ lead to the rejection of data for the $24 \mathrm{~h}$ involved.

Irregularities which occurred in measured spectra due to interference effects caused by reflection of sound from the ground surface or by perturbations during the propagation of aircraft noise to the microphone have been identified. Corrections have been applied to spectral characteristics which are not related to aircraft noise source. As specified in appendix 2 of Annex 16 of the ICAO convention, narrow band analysis is one recommended procedure for identifying these tones.

According to the measurement specifications, we identified and retained 15460 turbojet aircraft executing approaches of the airport in the same conditions representing $84.5 \%(+20 \mathrm{~T})$ of the air traffic $(15 \%$ of the air traffic represents propeller aircraft (3-9 $\mathrm{T}$ and $+20 \mathrm{~T})$ and $0.5 \%$ others $(-3 \mathrm{~T}$ and $3-9 \mathrm{~T})$ ). Because of the harmonic frequencies, propeller aircraft data were excluded from this analysis. The time and frequency signals are analyzed by the commercial DBTrait $\mathrm{C}$ software and by specific algorithms developed with Matlab $\left(\mathcal{C}\right.$ signal toolbox and $\mathrm{C}^{++} \mathrm{C}$ software computing spectral features of signals. The calculated parameter are noise levels, statistical indices, aircraft passage duration, spectra and the pure frequencies and frequency bands in the one-third octave characterized by the higher noise levels.

Aircraft noise on approach is considered as an unsteady state. Estimation of the power spectral density is often based on procedures employing the Fast Fourier Transform «FFT». This spectral analysis is computationally efficient in the large class of signal processing. But, its limitation - due to the windowing of data- occurs and manifests a leakage in the spectral domain. When high time and frequency resolution is needed, the Wigner-Ville or the Choi-Williams distributions are preferred [10,11, 21, 22, 26, 27]. This is performed by mapping a one dimensional signal in the time domain, into a two dimensional time-frequency representation of the signal. A variety of methods exist in the open literature, based on the Wigner-Ville distribution $[15,16]$. A separate analysis of a time domain or a frequency response is not sufficient to assess the behavioral aspect of the aircraft noise. Time-frequency distribution $[2,3,20]$, which associates each instant with a frequential representation of the signal, is recommended. It assesses aircraft noise frequencies corresponding to the raised levels. The discrete-time Wigner-Ville distribution $[1,4,7,25,26]$ is used in this paper. In order to reduce the cross-terms when the signal is composed by several components, the transform is smoothed in frequency by a Hanning window over 512 points. Figure 2 shows a typical time frequency spectrum of aircraft noise measured during three approaches. It gives an illustration of the used Wigner-Ville distribution.

The amplitude of the broadband noise in third-octave bands is determined by the average energy that remains in each band after removing all tonal components. An automatic search of maximum levels, pure frequencies and frequency bands were achieved. Aircraft noise varies both in frequency and level during a flight for three main different reasons. First, individual sound generating mechanisms each have a distinct frequency which depends on
Fig. 2 Time-frequency spectrum of three aircraft approaches

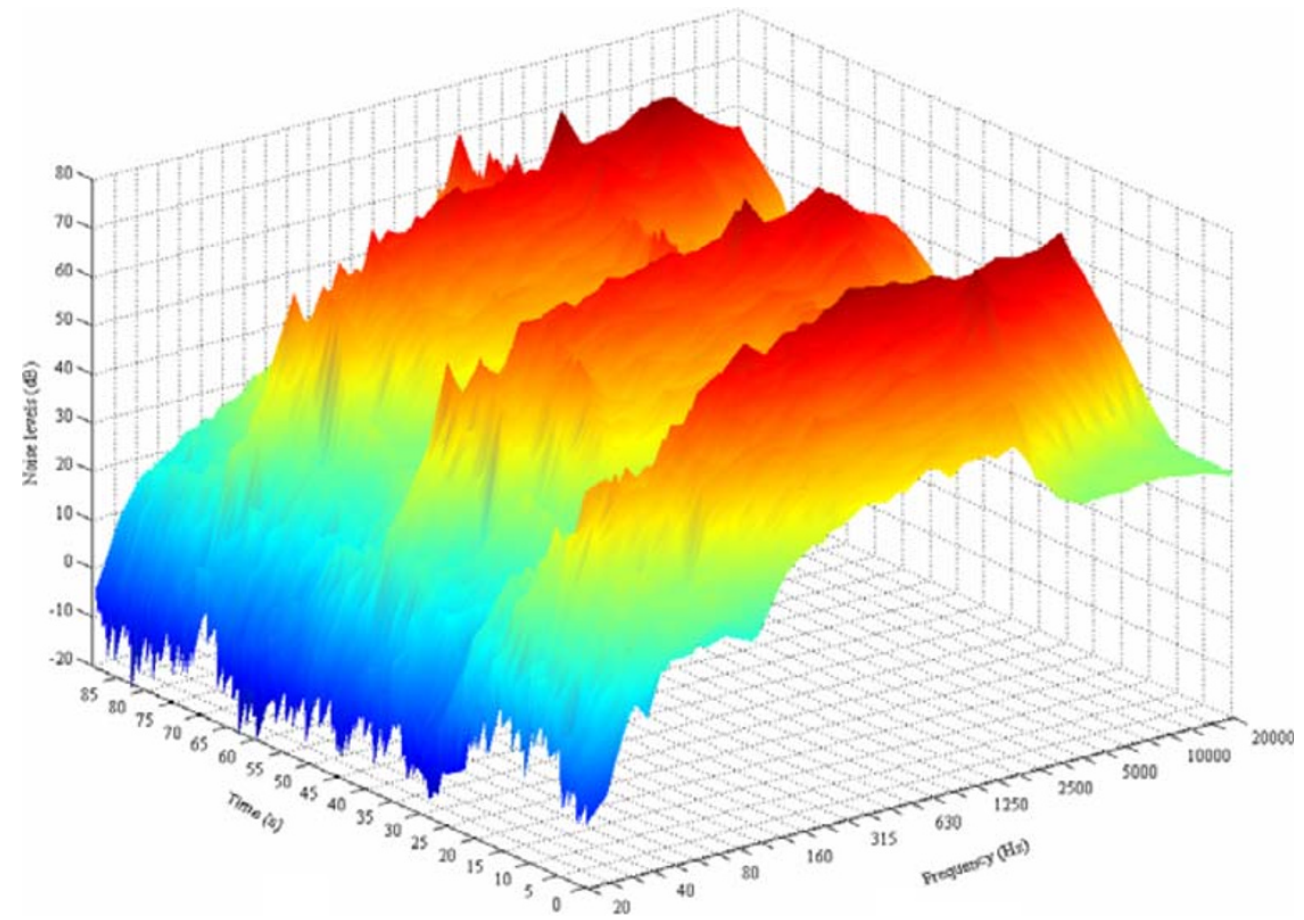


directivity. Second, owing to the directivity, the different sound component contributions dominate the sound radiation in different directions. Third, the measured noise levels are inclusively affected by Doppler Effect which modifies the frequency contents and the cumulated energy.

\section{Spectral methodology}

Aircraft directivity has a further impact on measurements and needs to be highlighted. It is asymmetric and may be expected to change in the future because of the effect of engine modifications. Aircraft directivity should become available in the coming years. Assessment of the directivity of a moving source is generally a complex problem because directivity functions may be described in various coordinate systems: fixed to the aircraft, fixed to the flight track or to the ground. Directivity and spectral content measured at a reception point could be particularly altered by the influence of forward speed. The Doppler Effect which changes the frequency content of the signal and the distribution of energy in time transforms the true radiated directivity into an apparent directivity as observed at a fixed receiver on the ground. Removing Doppler effects from recorded sound levels is a possible technique but requires very complex procedures. Because of this complexity, it seems more realistic to describe the source by its apparent spectral components measured at a fixed receiver position. Geometric calculations performed thereafter allow a correction of the Doppler Effect. Knowing the frequencies recorded at the receiver, we can assess the frequencies emitted by aircraft sources according to the emission angle $\theta_{\mathrm{j}}$ (Fig. 3) and the indicated aircraft speed. To remove the Doppler Effect, we first consider an aircraft as a source in motion where the receiver is placed under the track in $X_{j}$ position. The aircraft height $\mathrm{Z}$ is considered above the reference $(\mathrm{X}-\mathrm{Y})$ plane, generally taken to be the ground plane, with a microphone at $4 \mathrm{~m}$.

The receiver height is neglected. Measurements under the flight path avoid lateral angular corrections.

Analysis by Miyara et al. [23] gave at the reception point the observed frequency $f_{d}$ as:

$f_{d}=\frac{1-\frac{V_{w}}{c} \cos \left(\theta_{j}+3\right)}{1-\frac{V_{w}}{c} \cos \left(\theta_{j}+3\right)-M \cdot \cos \left(\theta_{j}\right)} f$

where $\theta_{\mathrm{j}}$ is the emission angle $\theta_{j}+\gamma_{i}+\alpha=\frac{\pi}{2}\left(\alpha=3^{\circ}\right)$. M Mach number. $V_{w}$ the wind speed. $f$ is the emitted turbojet engine frequency. Geometrical calculation allows the recovery of the pure frequencies of the source. For a given time $t$ and $\mathrm{X}_{\mathrm{j}}$,

$\alpha_{i}=\operatorname{artg}\left[\frac{X_{i} \cdot \operatorname{tg}\left(3^{\circ}\right)}{X_{i}-X_{j}}\right]$

Then, $\theta_{j}=87-\gamma_{i}$ and $\gamma_{i}=90-\alpha_{i}$. For $\mathrm{X}_{\mathrm{j}}$, we have divided the lateral interval into two parts for the purpose of calculation. For $\mathrm{X}_{\mathrm{i}} \in\left[0, \mathrm{X}_{\max }\right]$ (if $\mathrm{X}_{\max }=8,000 \mathrm{~m}$ corresponding to the lateral distance when almost all aircraft are aligned with respect to the axis of the main runway of the airport; $Z_{\max }=419 \mathrm{~m}$ ), we can write:

$\theta_{j}=\operatorname{artg}\left[\frac{X_{i} \cdot \operatorname{tg}\left(3^{\circ}\right)}{X_{i}-X_{j}}\right]-3 \forall \mathrm{X}_{\mathrm{i}} \in\left[\mathrm{X}_{\mathrm{j}}, \mathrm{X}_{\max }\right]$

In addition, $\beta_{k}=\operatorname{artg}\left[\frac{Z_{k}}{X_{j}-X_{k}}\right], Z_{k}=X_{k} \cdot \operatorname{tg}\left(3^{\circ}\right), \theta_{k}=$ $\xi_{k}+\tau_{k}, \xi_{k}=90-\beta_{k}$, then $\theta_{k}=177-\beta_{k}$ where:

$\theta_{k}=177-\operatorname{artg}\left[\frac{X_{k} \cdot \operatorname{tg}\left(3^{\circ}\right)}{X_{j}-X_{k}}\right] \forall \mathrm{X}_{\mathrm{k}} \in\left[0, \mathrm{X}_{\mathrm{j}}\right]$

Figure 4 shows the emission angle $\theta_{\mathrm{j}}$ behavior depending on the lateral distance for four $X_{\mathrm{j}}$ values under the flight path.
Fig. 3 Illustration of emission angles under flight path

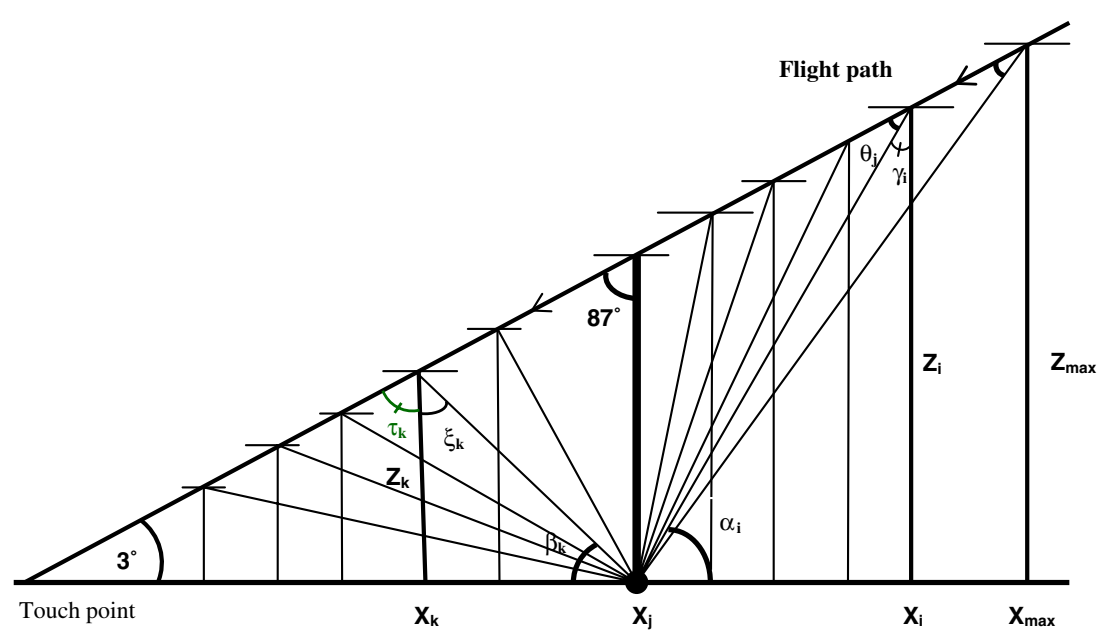




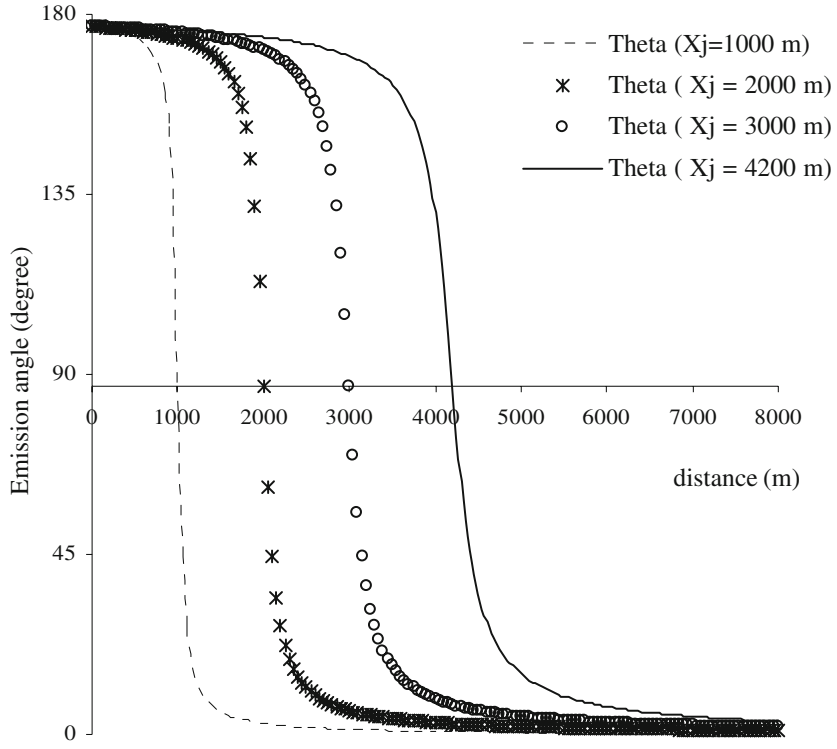

Fig. 4 Emission angle behaviour under flight path

In order to obtain the aircraft speed, two methods can be used. Either the aircraft speed is measured by the on-board instruments or assessed. The first method required a device ensuring a perfect data synchronization between on-board and ground instruments which was impossible. The second method, we used, is effective. It is based on frequency measurements and geometrical calculation. In order to obtain V, two conditions were chosen: $\mathrm{x}$ large and positive and $\mathrm{x}$ large and negative, yielding $\alpha_{i}$ close to 0 and $\pi$. This results in two equations (Eqs. 5, 6, 7) from which the frequency $f$ is eliminated and the system solved for constant speeds $\mathrm{V}$ :

for $\mathrm{x} \sim+\infty$, then the observed frequency:

$f_{+\infty}=\frac{c-V_{w}}{c-V_{w}-V \cos (\alpha)} f_{+}$

and for $\mathrm{x} \sim-\infty$, then the observed frequency:

$f_{-\infty}=\frac{c+V_{w}}{c+V_{w}+V \cos (\alpha)} f_{-}$

with $f_{+} \cong f_{-} \cong f$ the main engine frequency:

$V=\frac{c-V_{w}}{\cos (\alpha)}\left[\frac{f_{+\infty}-f_{-\infty}}{\frac{c-V_{w}}{c+V_{w}} f_{-\infty}+f_{+\infty}}\right]$

$f_{-\infty}$ is the observed frequency before the aircraft over-flight and $f_{+\infty}$ after. If we consider the receiver height $\mathrm{h}_{1}(4 \mathrm{~m}), h_{2}$, relation between the previous variables and angles, $f$ and $f_{d}$ (Eqs. 2, 4, 6, 7) can be easily written using the expression: $\theta_{j}=\frac{\pi}{2}-\alpha-\frac{X_{j}+\frac{h_{1}}{\operatorname{tg}\left(\alpha_{i}\right)}}{h_{2}}$ (Eq. 3; Fig. 5).

The interference arises between two sound waves as a combination of a direct and a reflected wave. Analysis by

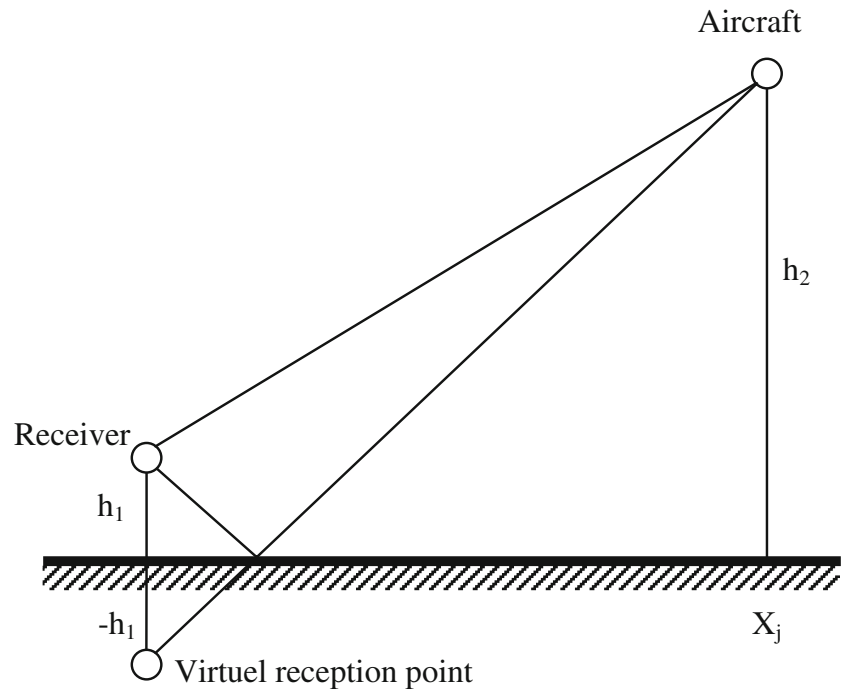

Fig. 5 Interference between direct and reflected sound waves responsible for the so-called "comb-filter" effect (Lloyd's mirror effect)

Smith [29] showed interference patterns caused by ground reflections, and the frequencies shown in the Fig. 6 using the following expressions: $f_{\text {cons }, j}=(j+1) \frac{c}{\Delta l}$ and $f_{\text {des }, j}=$ $(j+0.5) \frac{c}{N} \quad$ with $j=0,1,2, \ldots$, and $\Delta l$ the path length difference between the direct and the reflected sound wave; $\mathrm{c}$ is the sound speed, $f_{\text {cons }}$ and $f_{\text {des }}$ are respectively the frequency at which a constructive and destructive interference occurs.

As shown in the Fig. 6, the objective was to show that the frequencies which will be obtained in the following sections cannot in any case to be confused with those which correspond to the frequencies resulting from the constructive interference. The effect of destructive interference between direct and reflected sound waves at the microphone is not considered in this work because the unvested

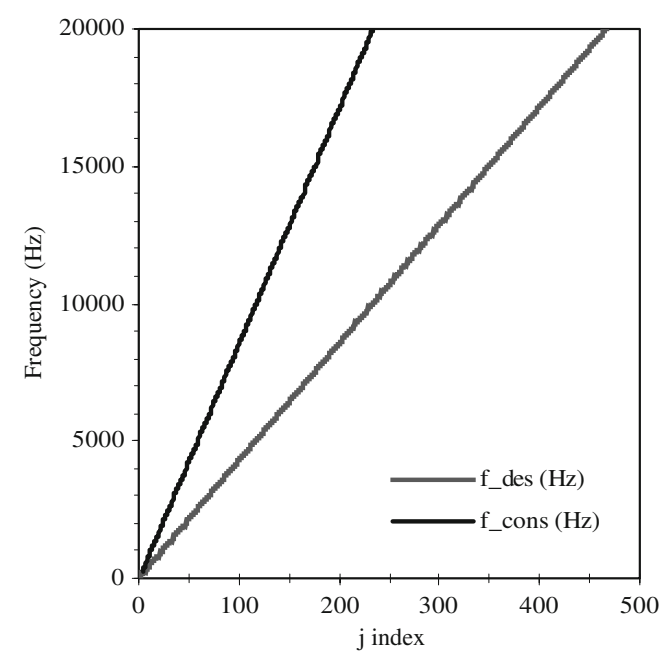

Fig. 6 Model of frequency interference 
frequencies are considered destroyed. A study by Miyara et al. [23] showed that the destructive interference effect could be used in the estimation of the aircraft's altitude. For outdoor experiments without any habitation, this effect does not occur. If we want to take this into account, as part of measures for assessing sound quality, we can use the results of Ferguson and Quinn [9], Schulten [28], and Miyara et al. [23]. They provide the conditions where Doppler patterns and comb filter are superimposed on the spectrogram Other research has been carried out by Lo et al. [22] who developed a model describing the temporal variations of the destructive interference for an aircraft approach. As far as we are concerned, the free field condition is filled and this combined effect neglected.

\section{Results and discussion}

The major frequency bands we have observed are $630 \mathrm{~Hz}$, $800 \mathrm{~Hz}, 1,000 \mathrm{~Hz}, 1,250 \mathrm{~Hz}$ and $1,600 \mathrm{~Hz}$ whose noise levels are the highest. The third-octave bands $1.25 \mathrm{kHz}$ and $1.6 \mathrm{kHz}$ are dominating. Their origin could be either the airframe of the aircraft, which upon landing with an engine rpm in slow motion may have a higher contribution of $10 \mathrm{~dB}$ above the noise of the engine or engines (combustion chamber and turbines) that emit broadband sounds between $1,500 \mathrm{~Hz}$ and $5,000 \mathrm{~Hz}$. At this stage, one cannot attribute these frequency bands to a particular source but to the whole aircraft (nacelle - components - engines). The pure dominating frequencies emitted by aircraft sources are evaluated for speeds between $56 \mathrm{~m} / \mathrm{s}$ and $150 \mathrm{~m} / \mathrm{s}$. These are the frequencies $800 \mathrm{~Hz}, 1,000 \mathrm{~Hz}, 1,142 \mathrm{~Hz}$ and $3,500 \mathrm{~Hz}$. Figure 7 shows these frequencies. The first frequencies are almost equal in energy to that of $3,500 \mathrm{~Hz}$. Their maximum intensities and their width at half height are: $800 \mathrm{~Hz}(77 \mathrm{~dB}, 32 \mathrm{~Hz}), 1,000 \mathrm{~Hz}(75 \mathrm{~dB}, 38 \mathrm{~Hz})$, $1,142 \mathrm{~Hz}(79 \mathrm{~Hz}, 38 \mathrm{~Hz})$ and $3,500 \mathrm{~Hz}(62 \mathrm{~dB}, 34 \mathrm{~Hz})$.

The observed frequency $1 \mathrm{kHz}$ was highlighted by Cremezi [5] and Cremezi and Legros [6] by modeling the propagation of noise emitted by aircraft in a complex and turbulent atmosphere. The study by Miyara et al. [23] has also highlighted the frequency of $1 \mathrm{kHz}$ during aircraft over-flights. The observed frequencies, not recovered by Cremezi calculation, are due to the fact that the engine was ignored or unknown in its modeling. A method of retrajectory simulation has subsequently been used by Cremezi to determine noise levels and spectra. Among the difficulties, resolution required a large number of approximations that simplified the overall problem. Cremezi confirmed that the model parameters are still quite sensitive, and interference generated by turbulence, may introduce significant differences with the experimental results. Moreover, the absence of the directivity of the
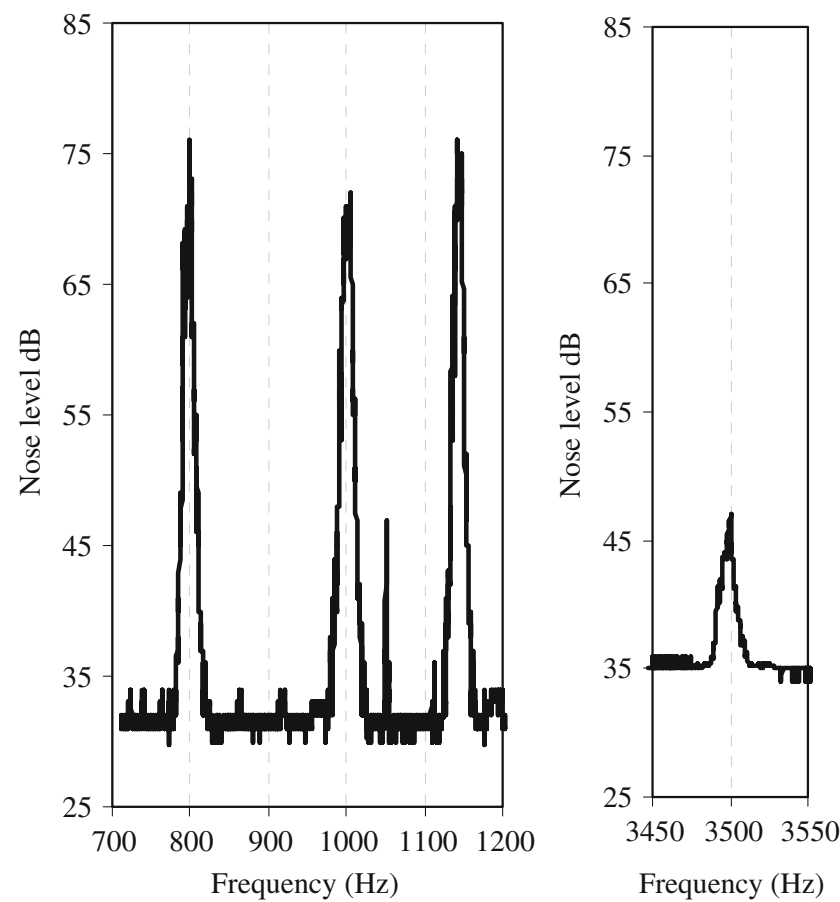

Fig. 7 Spectral analysis showing dominant frequencies

source in motion is an additional difficulty when making approximate calculations. The experimental results presented in this paper will certainly provide additional useful information to be used in theoretical models. The theoretical approach has difficulties due, in part, to simplifying approximations. The experimental approach is handicapped by the lack of aircraft FDR data. It can therefore be objectively argued that the combination of the two approaches contributes to a better understanding of the emitted frequencies problem that should be controlled by aircraft manufacturers. The frequency $3,500 \mathrm{~Hz}$ is characteristic of the fan noise. This noise, known to aircraft engine manufacturers, accounts for up to $7 \%$ of the noise on approach. However, we have no explanation for the observed frequency $1,142 \mathrm{~Hz}$. It could originate from the engines. Finally, some frequencies were not observed. They correspond to the low frequency noise $(50-500 \mathrm{~Hz})$ which may occur under certain weather conditions and engine operation. They result from the mixing of hot jet at the engine exit. The frequency $63 \mathrm{~Hz}$, observed by Miyara et al. was not found in this study, due to limitations of our measurement system at frequencies below $200 \mathrm{~Hz}$. Tonal components occurring between 1,000 and $7,000 \mathrm{~Hz}$ are particularly emitted by the turbine and the compressor for the turbojet engines. In addition, the latter can be generated by flows over cavities such as the landing gear box and flows on the level of the flaps. Also, it has been shown that from time to time the tonal components do not appear in a narrow frequency region but in a large interval of the spectrum. It can occur when tonal 
components have very close values or when the source frequencies have undergone fast changes around an average frequency. This phenomenon is significant for aircraft manufacturers because of active and passive controls implementation. Nevertheless, it has no meaning for the psycho-acoustic community because human hearing is often unable to distinguish close frequencies. Time-frequency spectra recorded from aircraft approaches did not show discrete tones due to rotational speed of the engine axis. In another way, to show the strong potential of this experimental work and its future prospects, we carried out a modeling of aircraft noise levels with the help of the existing empirical models by Zaporozhets and Khardi [35]. We used the generalized noise level calculation based on the following formula of individual aircraft movement:

$$
\begin{aligned}
L(t)= & L_{v e f}-20 \log _{10} R-\alpha R+\Delta L_{\text {atm }}+\Delta L_{\text {ground }} \\
& +\Delta_{f}+\Delta_{v}+\Delta_{D}
\end{aligned}
$$

where

$\alpha \quad$ the sound absorption coefficient

$\Delta \mathrm{L}_{\mathrm{atm}} \quad$ attenuation due to atmospheric absorption of sound by the air

$\Delta \mathrm{L}_{\text {ground }}$ attenuation or amplification due to ground or terrain effects

$\Delta_{\mathrm{f}} \quad$ spectral correction

$\Delta_{\mathrm{v}} \quad$ attenuation due to the divergence

$\Delta_{\mathrm{D}} \quad$ correction for duration

$\mathrm{R}$ the distance between the noise source and the observer (at the reception point)

$\mathrm{L}_{\text {ref }} \quad$ sound level at a reference distance $\mathrm{R}_{\text {ref }}$ (known) from the source (function of the power sitting).
The signs of $\Delta \mathrm{L}_{\mathrm{atm}}, \Delta \mathrm{L}_{\text {ground }}, \Delta_{\mathrm{f}}$ and $\Delta_{\mathrm{v}}$ are defined such that they are additive. The aircraft noise level $L$ (Eq. 8) is A-weighted level. Fundamentally, a model would employ one-third octave bands with important tonal components added as spectral lines. Doppler shift for a moving aircraft is directly related to the emission angle and aircraft speed, is simple to incorporate in general when air-to-ground propagation includes geometrical spreading and atmospheric absorption. When we tackle aircraft noise level calculations, if the considered point where we should provide noise levels is not placed beneath the flight path, but in lateral position, corrections have to be done for the excess attenuation by the ground.

As described previously, Doppler Effect explained by shifts of spectral peaks has to be considered when tonal components dominate over the broadband noise. The shifting is calculated by means of narrow band aircraft spectra. In our case, A-weighting jet noise $L_{r e f}$ is broadband in nature. Doppler Effect has then a small influence on the sound exposure; the receiver spectrum in the forward arc is shifted to higher frequencies where the sound absorption increases. In contrast, Doppler convection amplification has a significant role on the directivity during the flight. In this case, it is fundamental that Doppler Effect has to be considered. Correction for duration $\Delta_{\mathrm{D}}$ means that if the speed of the aircraft changes, duration of the emitted aircraft noise will change also and angular calculation previously given has to be used. Therefore, if the speed of the aircraft deviates from the reference speed, it is necessary to correct the change in duration within each flight path segment.

For $L_{r e f}$ (Eq. 8) calculation, we have used a semiempirical model of noise generated by conventional-
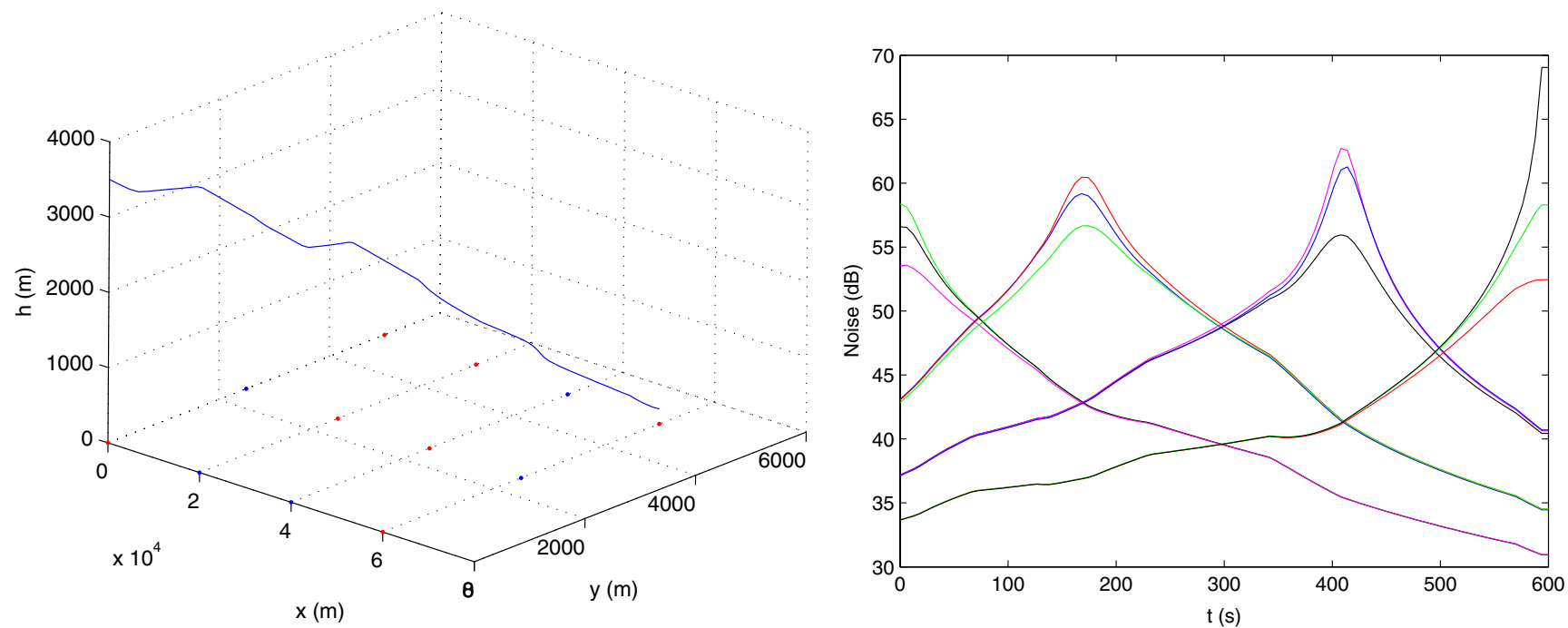

Fig. 8 Trajectory coordinates $(\mathrm{x}, \mathrm{y}, \mathrm{h})$ (left-sided) and the modeled maximum noise levels at twelve reception points (right-sided) at the point certification 
velocity-profile jets exhausting from coaxial nozzles [30]. It is known that jet noise consists of three principal components. They are the turbulent mixing noise, the broadband shock associated noise and the screech tones. At the present time, the first approximation has been used herein. It seems to be correct in that step of research because the problem complexity. Many studies have been shown to agree reasonably well with model and full-scale experimental data even at high jet velocities in the region near the jet axis [31-34] However, there is no known way to predict tone intensity and directivity; even if it is entirely empirical. This is not surprising for the tone intensity is determined by the nonlinearities of the feedback loop.

Obviously, to complete this study we will need to integrate other noise source models in particular aerodynamics taking into account spectral correction. During the descent phase, the aircraft jet noise is approximately omnidirectional and the noise emission is decreasing with decreasing speed when assuming that the power setting is constant. The predicted jet noise used in this paper is given in the free-field condition [30, 33]. The obtained results show that even the use of an optimized flight trajectory [19], aircraft noise values are lower in comparison with experimental recorded data (Fig. 8) because noise models of aircraft sources are not completely introduced. Differences are between 5 to $10 \mathrm{~dB}$.

In addition, frequential aspect cannot be explored with the existing theoretical models. That shows the interest to perform more experimental works with the aim to fully characterize frequency spectra of commercial aircraft noise during phase approaches.

\section{Conclusion}

This paper is specifically directed towards the search of the dominant pure frequencies of turbojet aircraft emitted during approaches which are responsible for noise disturbances surrounding airports.

A geometric study of frequency emission has been performed. Doppler corrections have been made and diagnosis of the effects of destructive interference examined. Dominant pure frequencies were observed and their analysis reveals an agreement with theoretical works. Their origin could come from the airframe of the aircraft, which upon landing with an engine rpm reduced to up to $55 \%$ can have a higher contribution of up to $10 \mathrm{~dB}$ above the noise of the engine. Experimental results presented in this paper could validate and extend calculation methods. They can provide additional useful information placing the results of theoretical models in context because of strong approximations for processing needs. We have used a semi-empirical model predicting the noise generated by conventional- velocity-profile jets exhausting from coaxial nozzles predicting the aircraft noise levels. The obtained noise values confirm that aircraft noise modelling is not sufficient to meet the precision of the processed experimental data for the characterization of frequencies in-flight. In addition, the relative sensitivity of acoustical indices confirms the need for further research concerning air traffic changes, type of aircraft, flight configurations, engines and their locations, EPR, fuel consumption...).

Acknowledgements This work is supported by the Rhône-Alpes Region (France) within the "Cluster TTS" framework. The author thanks the Rhône-Alpes Region.

\section{References}

1. Baraniuk RG, Jones DL (1993) A signal-dependent timefrequency representation: optimal kernel design. IEEE Trans Signal Process 41(4):1589-1602

2. Biscainho LWP, Diniz PSR, Esquef PAA (2001) ARMA processes in sub-bands with application to audio restoration. Proceedings of IEEE International Symposium on Circuits and Systems, Sidney 2 (2001), pp 157-160

3. Boashash B (2003) Heuristic Formulation of TFDs. In: Boashash B (ed) Time frequency signal analysis and processing: a comprehensive reference. Elsevier, Oxford, pp 29-57

4. Cohen L (1995) Time-frequency analysis. Prentice Hall, New Jersey

5. Cremezi C (2000) Etude de la propagation du son dans l'atmosphère: application au bruit des avions en phase d'approche et de décollage. Thèse de Doctorat

6. Cremezi C and Legros C (2000) Application de la méthode GF$\mathrm{PE}$ à une source élevée en mouvement. In Actes du $5^{\text {ème }}$ congrès français d'acoustique, EPFL, Lausanne (Suisse)

7. Czerwinski RN, Jones DL (1995) Adaptive cone-kernel timefrequency analysis. IEEE Trans Signal Process 43(7):1715-1719

8. ECAC (1997) European Civil Aviation Conference. Report on standard method of computing noise contours around civil airports. ECAC.CEAC Doc. 29 (2nd edn)

9. Ferguson B, Quinn B (1994) Application of the short-time Fourier transform and the Wigner-Ville distribution to the acoustic localization of aircraft. J Acoust Soc Am 96(2):Part 1

10. Griffin C (1991) A comparison study on the Wigner and ChoiWilliams distributions for detection. Proceedings of the Acoustics, Speech, and Signal Processing, 1991. ICASSP-91. IEEE Comput Soc: $1485-1488$

11. Hlawatsch F, Manickam TG, Urbanke RL, Jones W (1995) Smoothed pseudo-Wigner distribution, Choi-Williams distribution, and cone-kernel representation: ambiguity-domain analysis and experimental comparison Source. Signal Process 43:149-168 Elsevier North-Holland, Inc

12. ICAO (1988) Recommended method for the calculation of the noise level contours in the vicinity of airports. Circular 205-AN/1/ 25. International Civil Aviation Organization, Montreal

13. ICAO (1993) Aircraft Noise. Annex 16 to the Convention on International Civil Aviation. International Civil Aviation Organization, Montreal

14. ICAO (2004) Environment protection. Vol.1: aircraft noisespecifications for aircarft noise certification, noise monitoring, and noise exposure units for landuse planning. Available on http:// www.icao.int/ 
15. Jones DL, Baranuik (1994) A simple scheme for adapting timefrequency representations. IEEE Trans Signal Process 42:35303535

16. Jones DL, Baraniuk RG (1995) An adaptive optimal kernel timefrequency representation. IEEE Trans Signal Process 43 (10):2361-2371

17. Julliard J (2003) Bruit des turboréacteurs et dispositifs réducteurs. Dans S. Khardi, Journée Spécialisée«Réduction des bruits des avions commerciaux au voisinage des aéroports civils. Problématique, enjeux et perspectives». Actes $n^{\circ} 88,53-63$

18. Kannepalli C, Kenzakowski DC, Dash SM (2003) Evaluation Of Some Recent Jet Noise Reduction Concepts. Paper No. AIAA2003-3313, 9th AIAA/CEAS Aeroacoustics Conference \& Exhibit, Hilton Head, SC

19. Khardi S, Abdallah L (2008) Optimal trajectory reducing noise levels around airport (in progress)

20. Kwok HK, Jones DL (2000) Improved instantaneous frequency estimation using an adaptive short-time fourier transform. IEEE Trans Signal Process 48(10):2964-2972

21. Li M (1997) Experimental research for processing of ChoiWilliams distributionand Bessel distribution. Proc Int Conf Inf Commun Signal Process ICICS 3:1593-1597

22. Lo KW, Perry SW, Ferguson BG (1999) An image processing approach for aircraft flight parameter estimation using the acoustical Lloydapos; mirror effect. Signal Processing and Its Applications. ISSPA. Proceedings of the Fifth International Symposium on Digital Object Identifier 2:503-506

23. Miyara C, Cabanellas S, Mosconi P, Pasch V, Yanitelli M, Rall JC, Vasquez J (2001) The acoustical geometry of aircraft overflights. International Congress and Exhibition on Noise Control Engineering, Hague, pp 27-30
24. Oishi T, Nakamura Y (2000) Research on exhaust jet noise reduction technology. Ishikawajima-Harima Giho 40(2):65-67 ISSN 0578-7904. CODEN ISHGAV

25. Oppenheim AV, Schafer RW (1989) Discrete-time signal processing. Prentice-Hall, Englewood Cliffs

26. Orfanidis SJ (1988) Optimum signal processing, 2nd edn. McGraw-Hill

27. Papandreou A, Boudreaux-Bertels GF (1993) Generalization of the Choi-Williams distribution and the Butterworth distribution for time-frequency analysis. IEEE Trans Signal Process 41(1):463-498

28. Schulten JBHM (1997) Computation of aircraft noise propagation trough the atmospheric boundary layer. National Aerospace Laboratory NLR, Amsterdam

29. Smith MJT (1989) Aircraft noise. Cambridge University Press

30. Stone JR, Groesbeck DE, Zola Charles L (1981) An improved prediction method for noise generated by conventional profile coaxial jets. National Aeronautics and Space Administration. In Report NASA-TM-82712, AIAA-1991

31. Tam CKW (1995) Computational aeroacoustics: issues and methods. AIAA J 33:1788-1796

32. Tam CKW (1999) Supersonic jet noise. Annu Review Fluid Mech 27:17-43

33. Tam CKW (2001) Noise from high speed jets. Lecture notes. VKI lecture series on advanced in aeroacoustics. In: Anthoine J, Schram C, eds. Lecture series 2001-2002, pp 1, 34

34. Tam CKW, Auriault L (1999) Jet mixing noise from fine-scale turbulence. AIAA J 37(2):145-153

35. Zaporozhets OI, Khardi S (2004) Optimization of aircraft trajectories as a basis for noise abatement procedures around the airports. Theoretical considerations and acoustic applications. Les collections de l'INRETS. Rapport INRETS n² 257. 97 pages 